\title{
Development of a photovoltaic characteristics generator based on mathematical models for four PV panel technologies
}

\author{
Samia Jenkal ${ }^{1}$, Mustapha Kourchi ${ }^{2}$, Driss Yousfi ${ }^{3}$, Ahmed Benlarabi ${ }^{4}$, Mohamed Larbi Elhafyani ${ }^{5}$, \\ Mohamed Ajaamoum ${ }^{6}$, Mhand Oubella ${ }^{7}$ \\ 1,2,6,7 LASIME, ESTA, Ibn Zohr University, Morocco \\ ${ }^{3,5}$ Department of Electrical Engineering, National ENSA, Université Mohammed Premier, Morocco \\ ${ }^{4}$ Responsible for PV Systems at IRESEN, Morocco
}

\section{Article Info}

Article history:

Received Oct 9, 2019

Revised Jun 2, 2020

Accepted Jun 17, 2020

\section{Keywords:}

Emulator

Mathematical modeling

Matlab

Photovoltaic system

PV panel technologies

\begin{abstract}
A good study of photovoltaic system requests to have very precise current-voltage characteristic curves of photovoltaic modules for different technologies. The photovoltaic emulator provides an efficient solution to maintain the same current-voltage output of photovoltaic module. It includes three parts: the PV model, the control strategy, and the power converter. This paper provides three classes of modeling and simulation of photovoltaic arrays and presents the synthesis results of the current-voltage characteristic performances obtained by the modeling approaches. The models of the first class are based on electrical circuit model, those of the second class are based on multiple straight lines model, and for the third class, it is based on the look up table. The mathematical model is built using MATLAB/ Simulink, and an experimental bench was carried out to acquire an up-to-date and representative experimental database of four PV panels. This database is used for the validation of these models for the different PV panel technologies under Moroccan meteorological conditions. Following this comparative study, we came to a high agreement between the experimental and simulated current-voltage characteristics for the emulator under study.
\end{abstract}

Copyright $(2020$ Institute of Advanced Engineering and Science. All rights reserved.

\section{Corresponding Author:}

Samia Jenkal,

LASIME, Department of Electrical Engineering,

Ibn Zohr University,

B.P 33/S, Agadir 80000, Morocco.

Email: samia.jenkal@edu.uiz.ac.ma

\section{INTRODUCTION}

In recent years, Morocco has faced major challenges regarding the future of its energy system, economic growth and demographic growth [1]. Consequently, Morocco has implemented a national energy policy favorable to the development of renewable energies [2], to secure its energy supply, to control the future costs of energy services compared to the future costs of petroleum products and finally to preserve the environment by mitigating greenhouse gas emissions [3]. Photovoltaic solar energy represents an inexhaustible source of green energy and an alternative to fossil fuels [4]. The very high rate of growth of the energy industry means that the availability of specialized equipment for laboratory tests becomes crucial [5], in particular for manufacturers and laboratories working in the field of power electronics linked to PV installations. The obtained results require validation by appropriate experiments [6].

The photovoltaic emulator allows the validation of these tests by the modeling of the photovoltaic sources [7-9]. These mathematical models have a great effect on the proper functioning of these systems. It directly affects the static and dynamic performance of the photovoltaic emulator. The objective of this paper is the development of models that allows to better emulate the electrical characteristics of photovoltaic (PV) panels. This work is done on different technologies (Amorphous, CIS, Mono-Si, and CdTe) [10], and 
for different temperature and irradiation conditions [11]. These developed models will serve as the real-time control part of the photovoltaic emulators [12].

In this paper, we present in the first part of the studied methods to develop the generator of PV characteristics. The first method is deduced from the theory of semiconductors [13]; it takes the physical properties of PV cells as unknown. The second method uses models based on linear interpolation [8] and the third uses look up tables [14]. In the second part we describe the experimental system carried out and installed at Green Energy Park of Bengrire to have an updated and real experimental database of the meteorological conditions of Morocco then we present the collected database. The third part shows the results of the current-voltage characteristic obtained for the different technologies and based on the experimental system carried out which would be compared with the simulated results of the models proposed to confirm their validity.

\section{RESEARCH METHOD}

The modeling of the photovoltaic modules must represent their behavior with precision, without complicated mathematical operations that make the solutions difficult to obtain $[15,16]$. For this objective, three different models of PV are presented: The first is a classic model based on the electrical diagram of the photovoltaic cell. The second uses linear interpolation to reproduces the characteristics of PV panels, while the last is a purely experimental model, based on the LUT arrays.

\subsection{Electrical circuit model}

The electrical behavior of a PV module can be represented, according to the semiconductor theory, by a mathematical model with two exponentials or one exponential [7, 17-19]. In this work we used a single exponential model [20], allowing to obtain the models with five, four or two parameters.

\subsubsection{Five parameters model}

It is called a five parameters model, because the number of parameters necessary for the characterization and identification of the PV module is equal to 5: $\left(\mathrm{I}_{\mathrm{sc}}, \mathrm{V}_{\mathrm{oc}}, \mathrm{A}, \mathrm{R}_{\mathrm{s}}\right.$ and $\mathrm{R}_{\mathrm{p}}$ ). This model can be represented by the equivalent diagram in Figure 1, includes a current source $\mathrm{I}_{\mathrm{ph}}$ associated with a diode in parallel, modeling the P-N junction formed within the semiconductor making up the PV cell. To this association are added two resistances; one parallel $\mathrm{R}_{\mathrm{p}}$ and the other series Rs [21, 22].

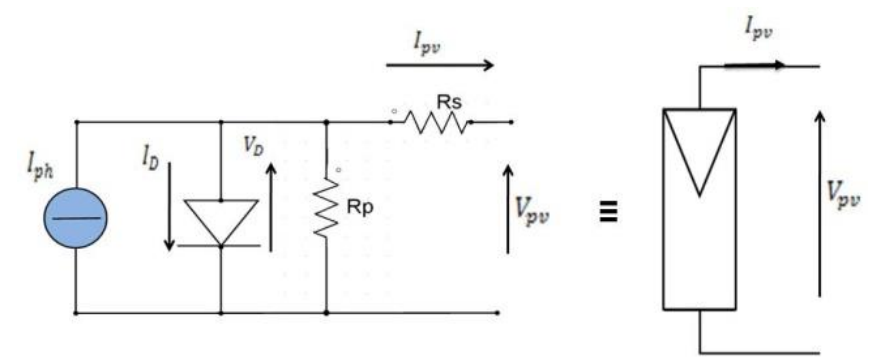

Figure 1. Equivalent circuit of a solar cell

According to Figure 1, the output current of the model is described as follows:

$$
\mathrm{I}_{\mathrm{ph}}-\mathrm{I}_{0}\left[\exp \left(\frac{\mathrm{V}_{\mathrm{pv}}+\mathrm{R}_{\mathrm{s}} \mathrm{I}_{p v}}{\mathrm{AV} \mathrm{V}_{\mathrm{t}}}\right)-1\right]-\frac{\mathrm{V}_{\mathrm{pv}}+\mathrm{R}_{\mathrm{s}} \mathrm{I}_{p v}}{\mathrm{R}_{\mathrm{p}}}-I_{p v}=0
$$

where:
Iph
: Photocurrent.
$\mathrm{I}_{0} \quad:$ Reverse saturation current for an ideal pn-junction diode.
A : Ideality factor of the solar cell.
$\mathrm{V}_{\mathrm{t}}=\mathrm{NsKT} / \mathrm{q} \quad$ : thermal voltage.
Ns $\quad$ : Number of cells connected in series.
K : Boltzmann's constant (1.38 10-23 J / K).
$\mathrm{T} \quad$ : Real junction temperature $(\mathrm{K})$. 
$\begin{array}{ll}\mathrm{Q} & : \text { : Elementary charge. } \\ \mathrm{R}_{\mathrm{s}} & : \text { Series resistance }(\Omega) . \\ \mathrm{R}_{\mathrm{p}} & : \text { Shunt resistance }(\Omega) .\end{array}$

The identification of these five parameters requires the resolution of the following:

$$
\left\{\begin{array}{l}
I=I_{p h}-I_{O}\left[\exp \left(\frac{V+R_{s} I}{A V_{t}}\right)-1\right]-\frac{V+R_{s} I}{R_{p}} \\
I_{O}=\frac{I_{s c}}{\exp \left(\frac{V_{o c}}{A V_{t}}\right)-1} \\
I_{p h}=\frac{R_{p}+R_{s}}{R_{p}} I_{s c}
\end{array}\right.
$$

where:

$\mathrm{I}_{\mathrm{sc}}$ : short-circuit current (A).

$\mathrm{V}_{\text {oc }}$ : open circuit voltage $(\mathrm{V})$.

\subsubsection{Two parameters model}

The idea in this model is based on the fact that under standard conditions, the current of a PV module can be expressed as a function of the voltage, by an expression containing a single simplified exponential as shown in (3):

$$
I_{n}=I_{s c n}\left\{1-C_{1}\left(\exp \left(\frac{V_{n}}{C_{2} V_{o c}}\right)-1\right)\right\}
$$

The two parameters $C_{1}$ and $C_{2}$ are calculated as a function of $I_{m p n}, V_{m p n}, V_{o c n}$ and $I_{s c n}$ under standard conditions:

$$
\begin{aligned}
C_{1}=\left(1-\frac{I_{m p n}}{I_{s c n}}\right) \exp \left(\frac{-V_{m p n}}{C_{2} V_{o c n}}\right) \\
C_{2}=\frac{\frac{V_{m p n}}{V_{o c n}}-1}{\log \left(1-\frac{I_{m p n}}{I_{s c n}}\right)}
\end{aligned}
$$

where:

$\mathrm{I}_{\mathrm{mpn}} \quad$ : maximum power current into (STC) (A).

$\mathrm{V}_{\mathrm{mpn}} \quad$ : maximum power voltage into (STC) (A).

In (3) allows to calculate the electrical characteristic $\mathrm{I}_{n}\left(\mathrm{~V}_{\mathrm{n}}\right)$ of the PV panel under standard conditions. The system of (6) allows the translating of the curve $\mathrm{I}_{\mathrm{n}}\left(\mathrm{V}_{\mathrm{n}}\right)$ to generate the characteristic $\mathrm{I}(\mathrm{V})$ corresponding to the new values of temperature and irradiation.

$$
\left\{\begin{array}{l}
V=V_{n} \frac{\ln (G)}{\ln \left(G_{n}\right)}\left(1+K_{v}\left(T_{c}-T_{c n}\right)\right) \\
I=I_{n} \frac{G \ln \left(G_{n}\right)}{G_{n} \ln (G)} \frac{\left(1+K_{m p}\left(T_{c}-T_{c n}\right)\right)}{\left(1+K_{v}\left(T_{c}-T_{c n}\right)\right)}
\end{array}\right.
$$

where:

$\mathrm{G} \quad$ : real illumination $\left(\mathrm{W} / \mathrm{m}^{2}\right)$.

$\mathrm{G}_{\mathrm{n}} \quad$ : Illumination in nominal STC $\left(\mathrm{W} / \mathrm{m}^{2}\right)$.

$\mathrm{K}_{\mathrm{v}} \quad$ : voltage temperature coefficient of the open circuit $\left(=80 \pm 10 \mathrm{mV} /{ }^{\circ} \mathrm{C}\right)$.

$\mathrm{T}_{\mathrm{cn}} \quad$ : Nominal temperature of the PV cell. 


\subsection{Piecewise linear model}

Interpolation is a mathematical operation allowing to replace a curve or a function by a simpler one that coincides with the first curve in a finite number of points given at the start. In this work we the linear interpolation [23], which consists of "joining the points" given by straight lines to subsequently estimate the rest of the points on the curve.

\subsubsection{Two lines approach}

This model is determined by adjusting the two lines to the three main points that characterize the $\mathrm{I}(\mathrm{V})$ characteristic: open circuit point, maximum power point and short-circuit point, as shown in Figure $2[8,17]$, it is represented by the following system of:

$$
\left[\begin{array}{l}
V_{m p}=V_{m p, n}+V_{t} \times \log \left(\frac{G}{G_{n}}\right)+K v \times\left(T-T_{n}\right) \\
I_{s c}=I_{s c, n} \times\left(\frac{G}{G_{n}}\right)+K\left(c i \times\left(T-T_{n}\right)\right) \\
I_{m p}=I_{m p, n} \times\left(\frac{G}{G_{n}}\right)+\left(K i \times\left(T-T_{n}\right)\right)
\end{array}\right.
$$

The two-line model is based on the knowledge of the four data items $I_{m p}, V_{m p}, V_{o c}$ and $I_{s c}$. Despite its lack of precision, the two-lines model is simple and allows the main appearance of $\mathrm{I}(\mathrm{V})$ characteristic to be represented.

\subsubsection{Four lines approach}

The objective of this model is to improve the accuracy [12], by selecting two other points: $\left(\left(V_{\mathrm{oc}}+\mathrm{V}_{\mathrm{mp}}\right) / 2, \mathrm{I}_{2}\right)$ and $\left(\mathrm{V}_{\mathrm{oc}} / 2, \mathrm{I}_{1}\right)$. As a result, we will have five points and four lines as shown in Figure 3.

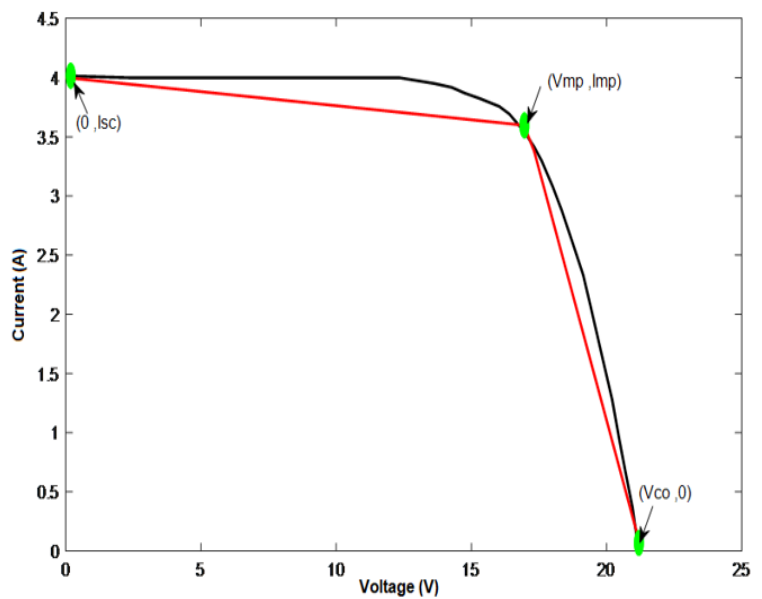

Figure 2. Two-lines interpolation model

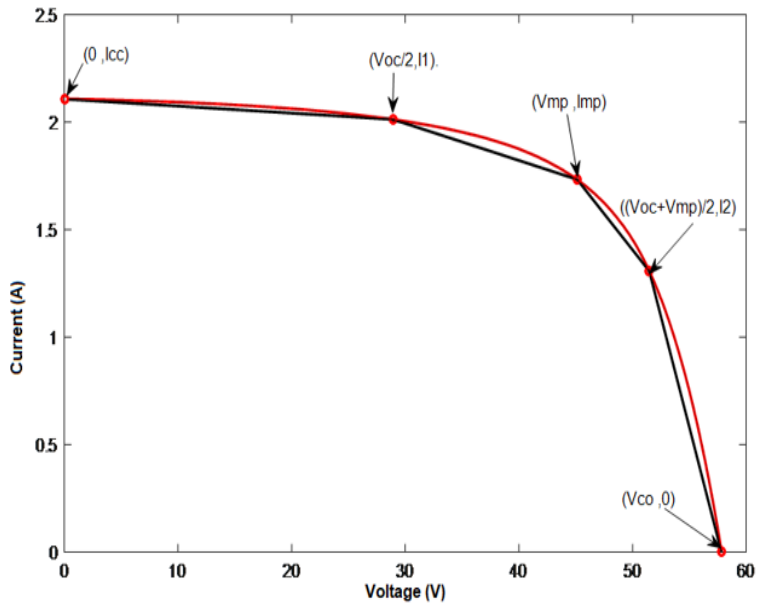

Figure 3. Four-lines interpolation model

The four equations representing the four lines are given by:

$$
\begin{cases}I=I_{2}-I_{2} \frac{V-V_{2}}{V_{O C}-V_{2}} & \text {; if } V_{2} \leq V \leq V_{o c} \\ I=I_{m p}+\left(I_{2}-I_{m p}\right)\left(\frac{V-V_{m p}}{V_{2}-V_{m p}}\right) & \text {; if } \quad V_{m p} \leq V \leq V_{2} \\ I=I_{1}+\left(I_{m p}-I_{1}\right)\left(\frac{V-V_{1}}{V_{m p}-V_{1}}\right) & \text {; if } V_{1} \leq V \leq V_{m p} \\ I=I_{s c}+\left(I_{1}-I_{s c}\right)\left(\frac{V}{V_{l}}\right) & \text {; if } 0 \leq V \leq V_{1}\end{cases}
$$


where: $\quad V_{1}=\frac{V_{o c}}{2} \quad$ and $\quad V_{2}=\frac{V_{o c}+V_{m p}}{2}$

\subsection{Look up table model}

The look up table (LUT) approach, is based on the acquisition of all possible I(V) data of a real PV field under different climatic conditions (temperature, illumination, etc.), and on the storage of these data in appropriate unit. This method avoids any mathematical link between current and voltage. The I(V) characteristic is generated by a direct linear interpolation of the experimental data tables. The generator of $\mathrm{I}(\mathrm{V})$ characteristics in our PV emulator is a look-up-table with four dimensions $(\mathrm{V}, \mathrm{I}, \mathrm{G}, \mathrm{T})$, as shown in Figure 4. The current $\mathrm{I}$ is a function of the illumination $\mathrm{G}$, temperature of module $\mathrm{T}$ and voltage $\mathrm{V}$ of PV module.

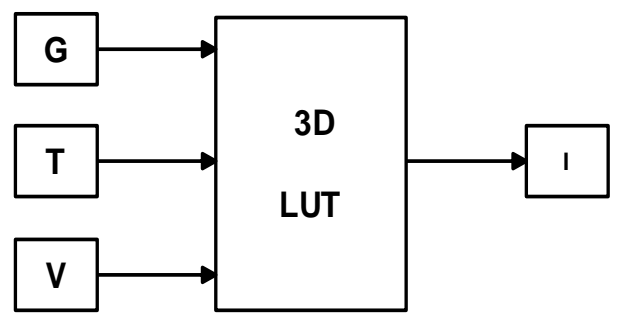

Figure 4. Look up table model in Matlab/Simulink

\section{RESULTS AND DISCUSSION}

\subsection{Experimental bench}

The validation of the proposed models requires an up-to-date experimental database that represents the meteorological conditions of Morocco. For thus, we have located the experimental bench at Green Energy Park in Benguerir City, allowing the recording of the $\mathrm{I}(\mathrm{V})$ characteristics corresponding to a duration of 56 days. These registrations concerned four PV modules of different technologies: monocrystalline silicon, microcrystalline amorphous, cadmium telluride and CIS.

Data is captured with a 10 minutes sampling period throughout the day. It contains the illumination, module temperature, current and voltage data provided by the PV modules. The data is collected using an active load, a temperature sensor (pt 1000), a sun sensor (hemispherical solar radiation), and a data acquisition server (PV Analyzer - SQL Connect Center, as illustrated in Figure 5. The results are validated by four PV technologies. Table 1 summarizes the electrical characteristics of the PV technologies studied.

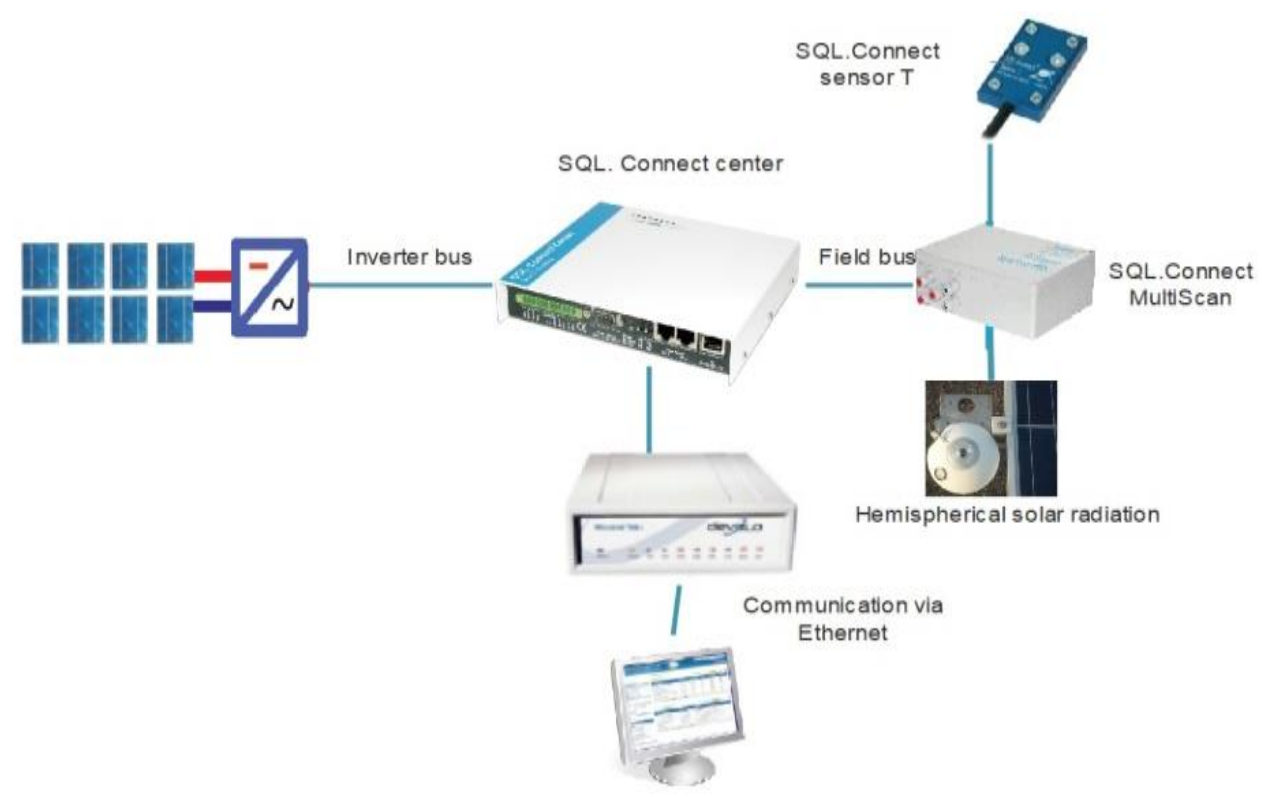

Figure 5. The experimental bench at Green Energy Park in Benguerir City 
Table 1. Typical electrical characteristics of solar modules studied

\begin{tabular}{ccccc}
\hline Module PV & SHARP NS-F135G5 [24] & Power Max STRONG 120 [25] & TSM-DC01A [26] & CALYXO CX3 [27] \\
\hline Material & Amorphe/Microcrystalline & CIS & Mono-Si & Cdte \\
Voc (V) & 61.3 & 58.3 & 45.1 & 62 \\
Isc (A) & 3.41 & 3.22 & 5.52 & 1.92 \\
Vmp (V) & 47 & 42.8 & 36.8 & 46.6 \\
Imp (A) & 2.88 & 2.81 & 5.18 & 1.68 \\
Pmax (W) & 135 & 120 & 190 & 77.5 \\
Ns & -- & -- & 72 & -- \\
$\mathrm{Kv} \% /{ }^{\circ} \mathrm{C}$ & -0.3 & $-170 \mathrm{mV} /{ }^{\circ} \mathrm{C}$ & -0.35 & -0.24 \\
$\mathrm{Ki}$ & $0.07 \% /{ }^{\circ} \mathrm{C}$ & $0.1 \mathrm{~mA} /{ }^{\circ} \mathrm{C}$ & $0.05 \% /{ }^{\circ} \mathrm{C}$ & $0.02 \% /{ }^{\circ} \mathrm{K}$ \\
$\mathrm{Kmp}\left(\% /{ }^{\circ} \mathrm{C}\right)$ & -0.24 & $-0.39 \% /{ }^{\circ} \mathrm{C}$ & -0.45 & -0.25 \\
$\mathrm{NOCT}\left({ }^{\circ} \mathrm{C}\right)$ & -- & -- & 46 & 45 \\
\hline
\end{tabular}

\subsection{Evaluation criteria}

The coefficient of determination $\mathrm{R}_{\mathrm{d}}$ and the mean square error RMSE, are calculated to evaluate the precision of the parameters for each technology studied [28]. $R_{d}$ is a quality indicator of linear regression. It describes the effect of the independent variable on the dependent variable. The value of this coefficient is taken between 0 and 1 . It is calculated according to (9).

$$
R_{d}=1-\frac{\sum_{i=1}^{N}\left(G_{m e s}(i)-G(i)\right)^{2}}{\sum_{i=1}^{N}\left(G_{m e s}(i)-\overline{G_{m e s}}\right)^{2}}
$$

where: $\overline{G_{\text {mes }}}=\frac{\sum_{i=1}^{N} G_{\text {mes }}(i)}{N}$ is the arithmetic mean of the measured quantity G.

The RMSE mean square error describes the difference between the values predicted by a model and the values actually observed. It is calculated according to the formula in (10).

$$
R M S E=\sqrt{\sum_{i=1}^{N} \frac{\left(G_{i \text { mes }}-G_{i c a l}\right)^{2}}{N}}
$$

Furthermore, we calculated the average computation time $t_{\mathrm{CPU}}$, to estimate the speed execution of each processed models.

\subsection{Results and discussion}

Based on the experimental data collected from the Green Energy Park in Benguerir City, for each PV technology studied, the experimental characteristics are compared to the simulation results of models that have been developed. The results obtained, allow finding the most efficient model, which gives the best correlation compared to the experimental I(V) curves, for the four PV technologies. Figures 6, 7, 8, 9 and 10 respectively show the results of applying the 5-parameters, 2-parameters, 2-lines, 4-lines and LUT model for the four PV panel technologies. The I(V) characteristics are given for different values of illumination and temperatures.

In all studied cases, we clearly notice that the simulated values agree with the experimental measurements. At some power range, they are literally identical. To evaluate the accuracy of each model, Table 2 summarizes the values calculated for the coefficient of determination $R_{d}$ and the mean square error RMSE. The comparison of the different models' performances requires the calculation of the average values of the different criteria as shown in Table 3 .

The analysis of the results presented on Tables 2 and 3, shows a high compromise in precision and speed of execution by the 5-parameters model $\left(\mathrm{R}_{\mathrm{d}}=0.993, t_{C P U}=0.16 \mathrm{~s}\right)$, and 4-lines model $\left(\mathrm{R}_{\mathrm{d}}=0.989\right.$, $\left.t_{C P U}=0.03 \mathrm{~s}\right)$. The LUT model is less precise but it still the fastest $\left(\mathrm{R}_{\mathrm{d}}=0.96, t_{C P U}=0.01 \mathrm{~s}\right)$. As an economic study is required for the design of photovoltaic emulator, and since the low-cost micro-controllers has memory limitation issues, the four lines approach is the most appropriate for modeling $\mathrm{I}(\mathrm{V})$ curves of the PV panel. 

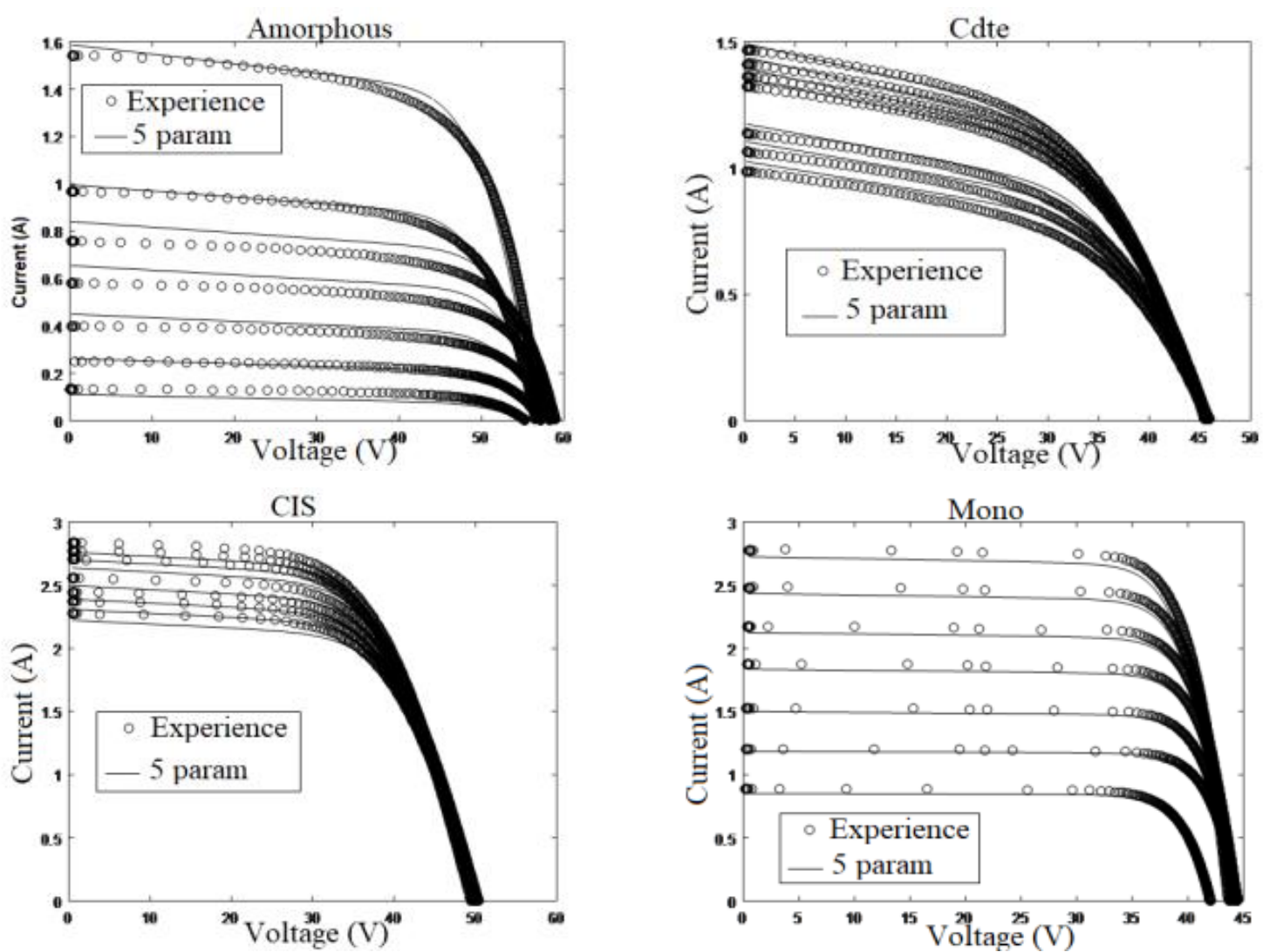

Figure 6. Comparison between experimental and simulated I(V) characteristics of the five-parameters model
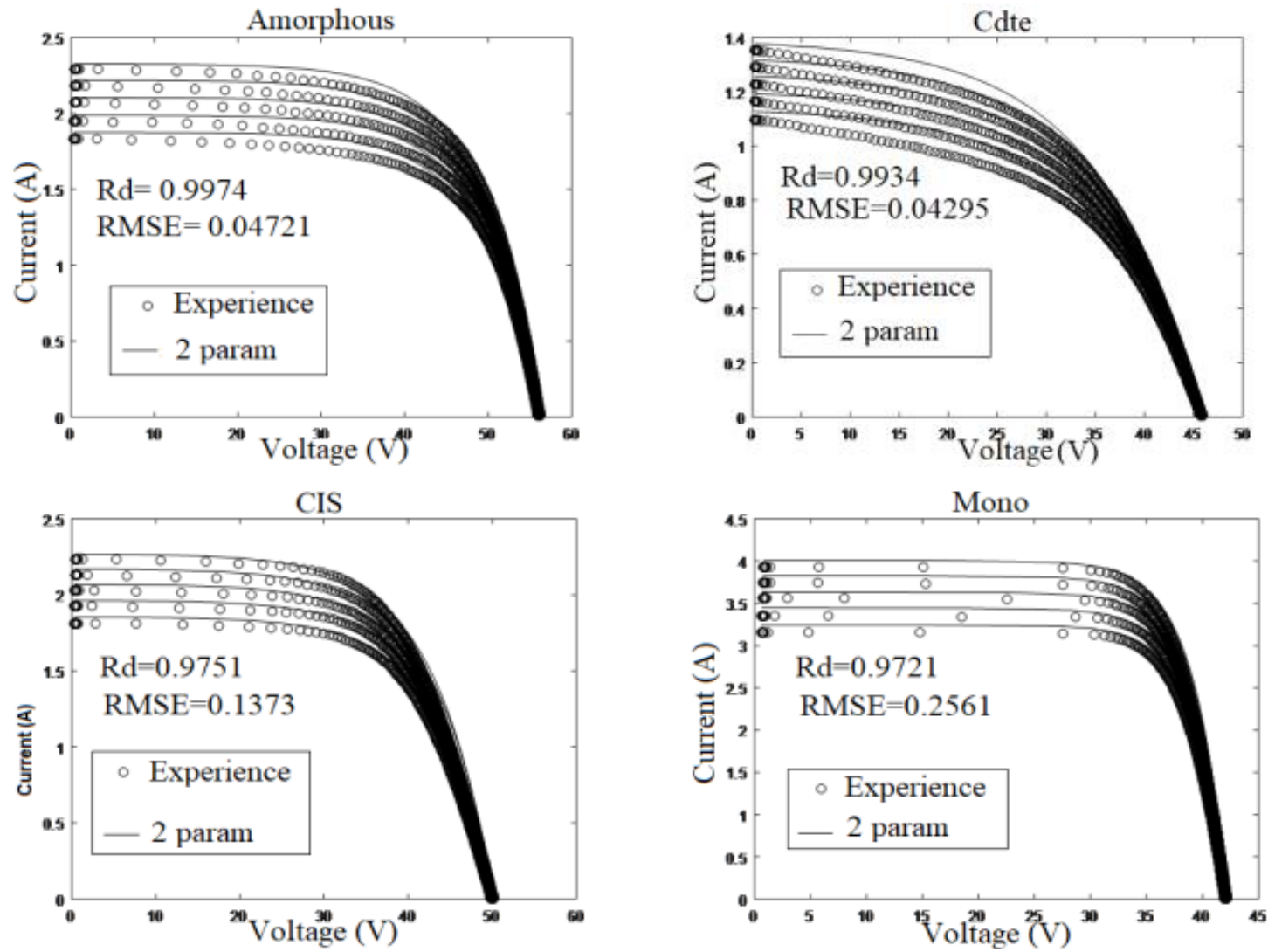

Figure 7. Comparison between experimental and simulated I(V) characteristics of the two-parameters model 

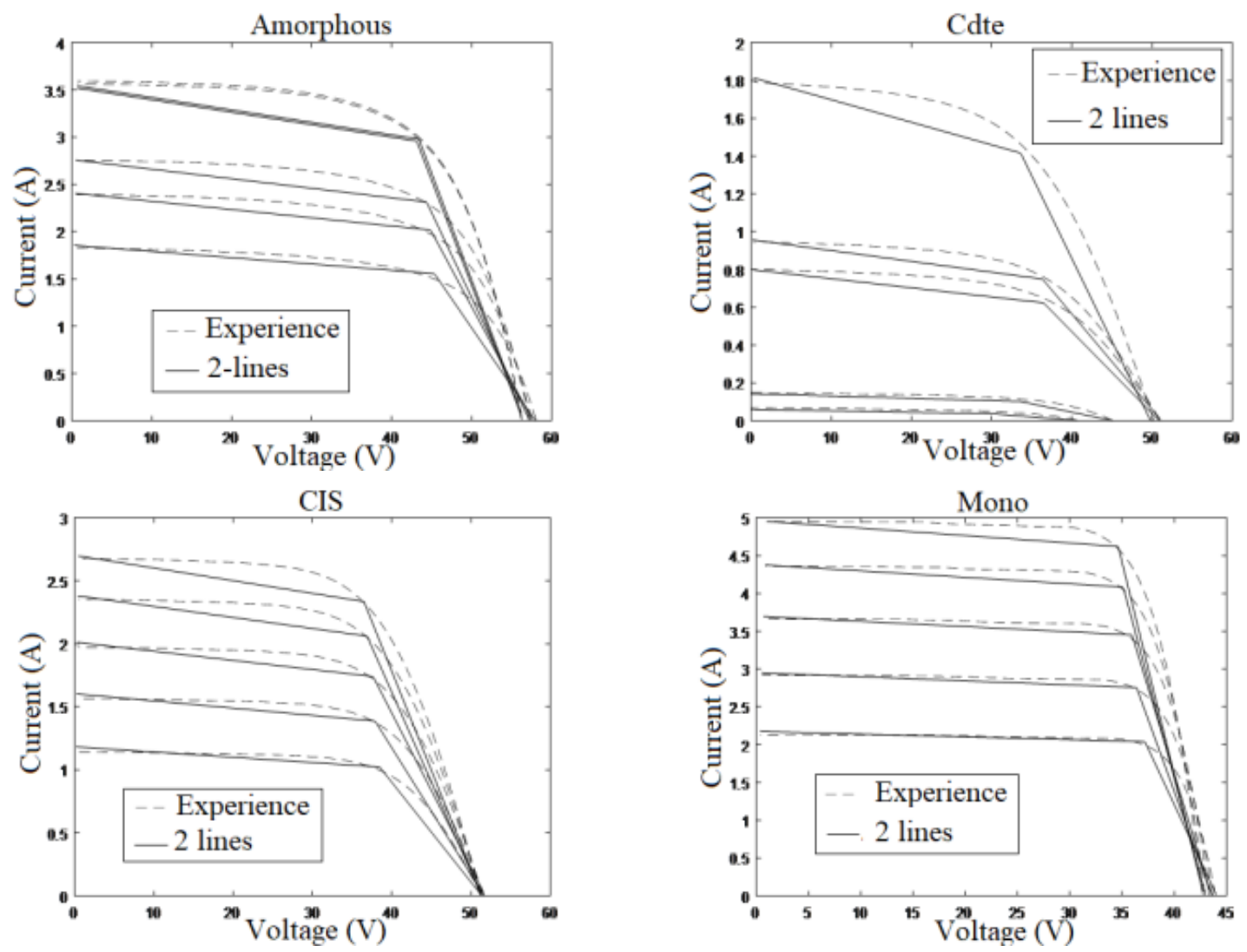

Figure 8. Comparison between experimental and simulated I(V) characteristics of the two-lines model
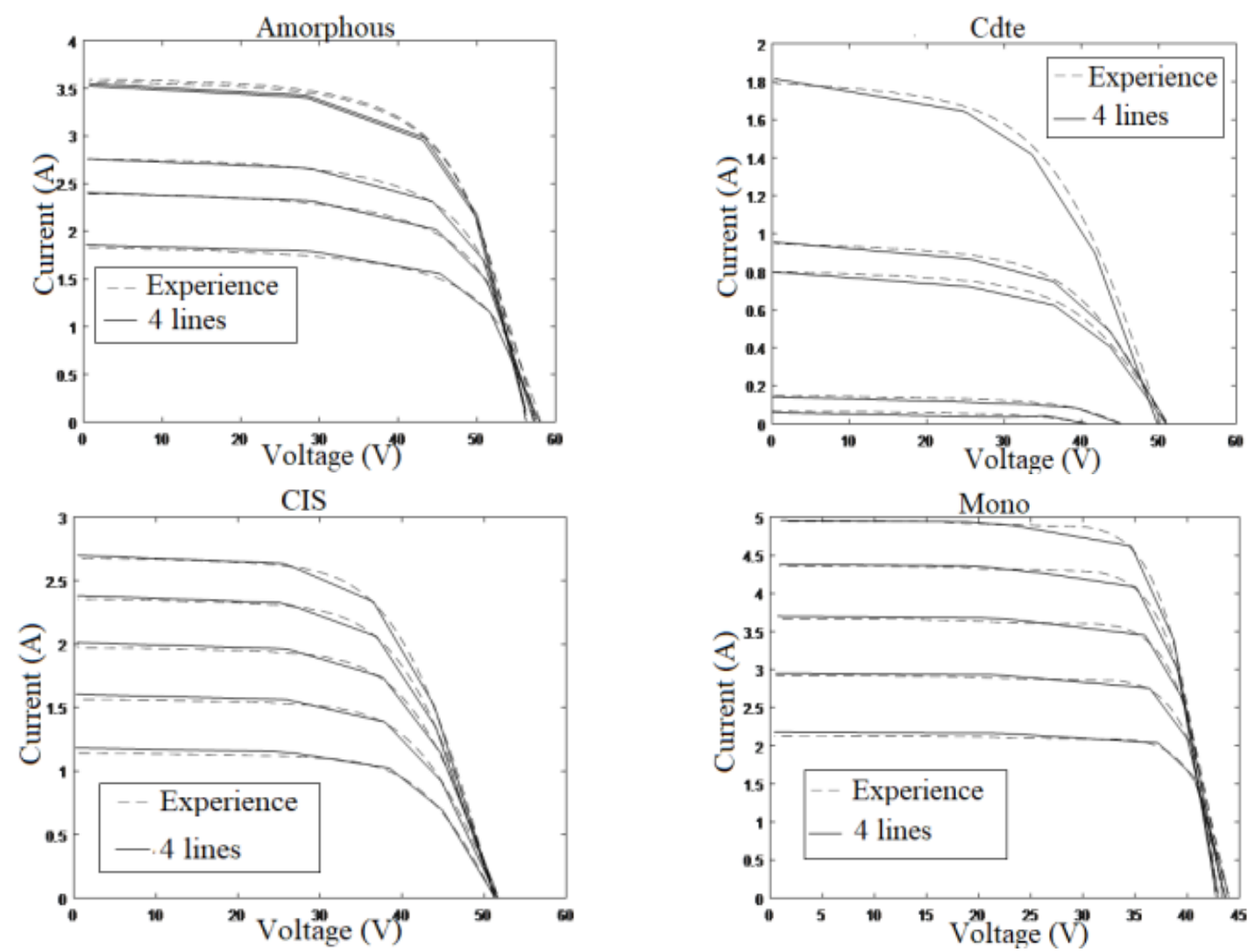

Figure 9. Comparison between experimental and simulated I(V) characteristics of the Four-lines model 

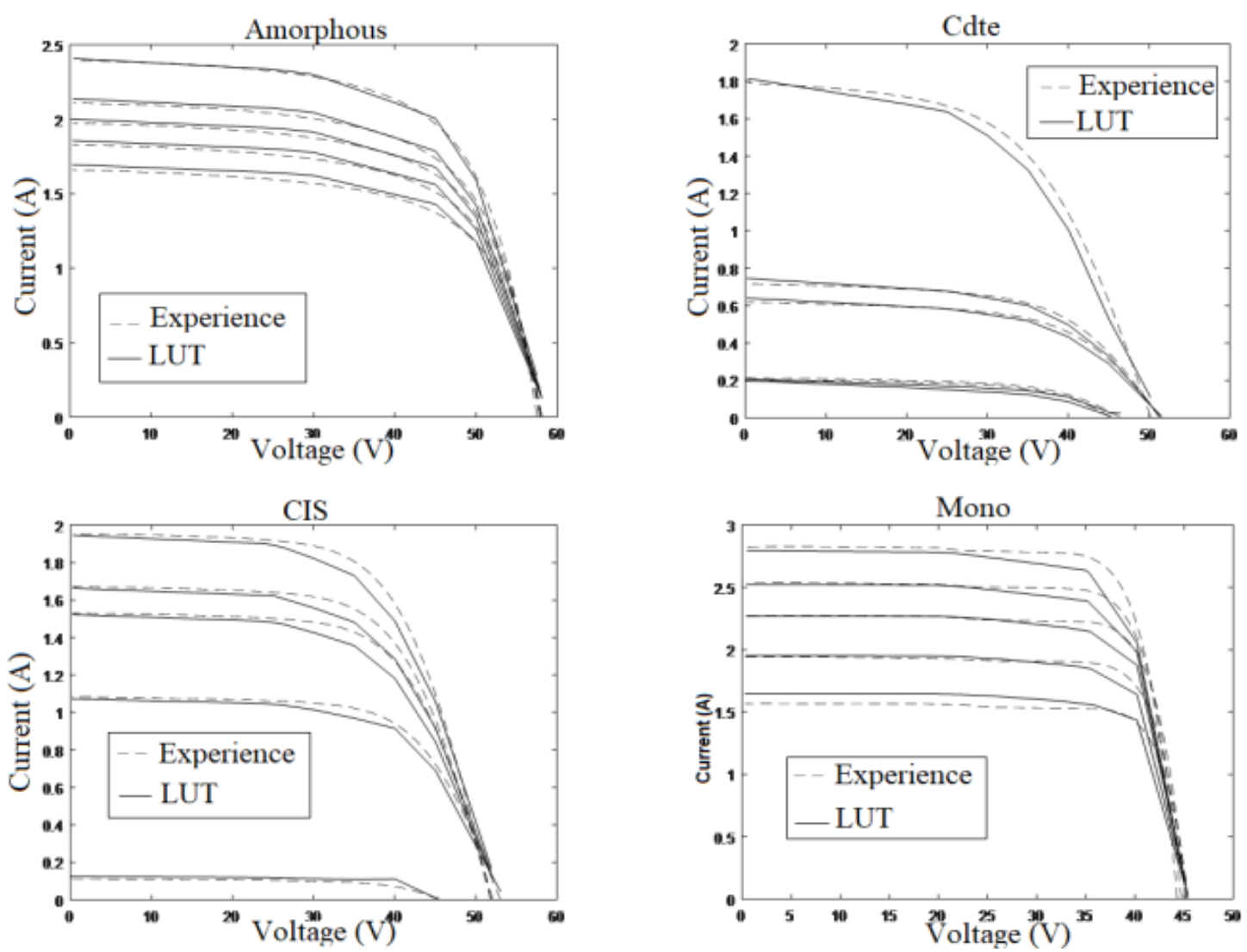

Figure 10. Comparison between experimental and simulated I(V) characteristics of the LUT model

Table 2. Summary of the performance of models studied

\begin{tabular}{ccccccc}
\hline Technology & Criterion & 5 parameters & 2 parameters & 2 lines & 4 lines & LUT \\
\hline SHARP & $R_{d}$ & 0.9887 & 0.9974 & 0.8771 & 0.9864 & 0.9643 \\
NS-F135G5 Amorphe & $R M S E$ & 0.0982 & 0.0472 & 0.3235 & 0.9864 & 0.1743 \\
& $t_{C P U}(\mathrm{~s})$ & 0.1654 & 0.0370 & 0.0369 & 0.0398 & 0.0081 \\
Calyxo & $R_{d}$ & 0.9973 & 0.9934 & 0.9580 & 0.9966 & 0.9952 \\
Cx3 & $R M S E$ & 0.0277 & 0.0429 & 0.1087 & 0.0308 & 0.0368 \\
Cdte & $t_{C P U}(\mathrm{~s})$ & 0.3581 & 0.0445 & 0.0385 & 0.0366 & 0.0081 \\
Power Max STRONG 120 CIS & $R_{d}$ & 0.9980 & 0.9751 & 0.9390 & 0.9948 & 0.9770 \\
& $R M S E$ & 0.0389 & 0.1373 & 0.2151 & 0.0626 & 0.1320 \\
TSM-DC01A & $t_{C P U}(\mathrm{~s})$ & 0.1643 & 0.0399 & 0.0372 & 0.0369 & 0.0101 \\
Mono-Si & $R_{d}$ & 0.9950 & 0.9721 & 0.8251 & 0.9834 & 0.9322 \\
& $R M S E$ & 0.1080 & 0.2561 & 0.6406 & 0.1974 & 0.3989 \\
& $t_{C P U}(\mathrm{~s})$ & 0.0677 & 0.0370 & 0.0302 & 0.0372 & 0.0082 \\
\hline
\end{tabular}

Table 3. Summary of the average criteria for the four technologies

\begin{tabular}{cccccc}
\hline Average criteria & 5 parameters & 2 parameters & 2 lines & 4 lines & LUT \\
\hline$R_{d}$ & 0.99382 & 0.98292 & 0.90666 & 0.98942 & 0.96258 \\
$R M S E$ & 0.10726 & 0.17782 & 0.3936 & 0.31832 & 0.26954 \\
$t_{C P U}(\mathrm{~s})$ & 0.1632 & 0.05138 & 0.0385 & 0.03908 & 0.0102 \\
\hline
\end{tabular}

\section{CONCLUSION}

The aim of this article is the development of a photovoltaic characteristic generators based on mathematical models. The parameters estimation problem is solved using a system of equations determined using the electrical circuit method, the linear interpolation method, and the LUT model. The experimental validation of these models is done for four technologies: monocrystalline silicon (TSM-DC01A), microcrystalline amorphous (SHARP NS-F135G5), CIS (Power Max STRONG 120) and CdTe (Calyxo Cx3 Cdte). The test bench has been located at Green Energy Park in Benguerir City, Morocco, allowing the recording of the $\mathrm{I}(\mathrm{V})$ characteristics of PV panels. The results show that the proposed models are very precise and agree with the experimental measurements. A comparative study is performed in order to find 
the high accuracy model and it have demonstrated that the 4-lines model is fast, accurate and straight-forward $\left(\mathrm{R}_{\mathrm{d}}=0.989\right.$, $\left.\mathrm{RMSE}=0.318, t_{C P U}=0.03 \mathrm{~s}\right)$. Otherwise, it is planned as a future perspective, to realize this emulator in order to apply these models as well as develop other methods of emulation.

\section{REFERENCES}

[1] K. Choukri, A. Naddami, and S. Hayani, "Renewable energy in emergent countries : Lessons from energy transition in Morocco," Energy, Sustain. Soc., vol. 7, no. 1, pp. 1-11, 2017.

[2] "Ministry of Energy, Mines, Water and Environment, National energy strategies horizon 2030-frensh version," [Online], Available: http://giz-energy.ma/wp-content/uploads/sites/128/2017/06/STRATEGIE-ENERGETIQUENATIONALE 2011.pdf.

[3] F. Outferdine, et al., "Feasibility of substitution of the conventional street lighting installation by the photovoltaic case study on a municipality in agadir in morocco," International Journal of Electrical and Computer Engineering (IJECE), vol. 7, no. 5, pp. 2287-2299, 2017.

[4] W. Hoffmann, "PV solar electricity industry: Market growth and perspective," Sol. Energy Mater. Sol. Cells, vol. 90, no. 18-19, pp. 3285-3311, 2006.

[5] H. Can, "Model of a photovoltaic panel emulator in MATLAB-Simulink," Turkish Journal of Electrical Engineering and Computer Sciences, vol. 21, no. 2, pp. 301-308, 2013.

[6] X.U. Jianzhong, A. Assenova, V. Erokhin, "Renewable energy and sustainable development in a resource-abundant country: Challenges of wind power generation in Kazakhstan," Sustainability, vol. 10, no. 9, pp. 1-21,2018.

[7] L. Adriana and T. Grisales, "Tecnura," Tecnura, vol. 20, no. 48, pp. 171-183, 2016.

[8] D. D. C. Lu and Q. N. Nguyen, "A photovoltaic panel emulator using a buck-boost DC/DC converter and a low cost micro-controller," Sol. Energy, vol. 86, no. 5, pp. 1477-1484, 2012.

[9] O. Oussalem, M. Kourchi, A. Rachdy, M. Ajaamoum, H. Idadoub, and S. Jenkal, "A low cost controller of PV system based on Arduino board and INC algorithm,” Materials Today: Proceedings, vol. 24, pp. 104-109, 2020.

[10] B. Brahim, B. Lahoussine, and I. Ahmed, "Comparative study of the performance improvement of four pv technologies controlled by a solar tracker-case of Agadir City in Morocco," Semanticscholar, vol. 5, no. 12, pp. 11-16, 2016.

[11] O. Oussalem et al., "Realization of a control platform of a photovoltaic system optimized by MPPT strategy "perturb and observe," Int. Rev. Autom. Control, vol. 12, no. 3, pp. 115-122, 2019.

[12] M. Ajaamoum, et al., "Photovoltaic panel emulators, design and implementation using rapid prototyping technique," International Review of Electrical Engineering, vol. 9, no. 5, pp. 1012-1020, 2014.

[13] K. Ukoima and E. O. Agwu, "Three-diode model and simulation of photovoltaic (PV) cells," Umudike Journal of Engineering and Technology, vol. 5, pp. 108-116, 2019.

[14] I. Houssamo and Contribution, "Contribution à l'étude théorique, à la modélisation et à la mise en œuvre d'un système multisource appartenant à un micro-réseau électrique - Contribution to the theoretical study, the modeling and the implementation of a multisource system belonging to an electrical micro-network (in French)," Considérations sur la qualité de l'énergie, 2015.

[15] R. Ayop and C. W. Tan, "A comprehensive review on photovoltaic emulator," Renewable and Sustainable Energy Reviews, vol. 80, pp. 430-452, 2017.

[16] M. C. Di Piazza and G. Vitale, "Photovoltaic sources: modeling and emulation," Springer Science \& Business Media., pp. 76-86, 2013.

[17] R. Szabo and A. Gontean, "Photovoltaic Cell and Module I-V Characteristic Approximation Using Bézier Curves," Applied Sciences, vol. 8, no. 5, 2018.

[18] R. Khenfer, "Détection et isolation de défauts combinant des méthodes à base de données appliquées aux systèmes électro-énergétiques Soutenu," Diss., 2005.

[19] E. I. Banu, P. Eng, and M. Istrate, "Modeling And Simulation Of Photovoltaic Arrays," Buletinul AGIR, 2014.

[20] S. Jenkal, et al., "Design and implementation of an agilent-based platform for PV feature generator based on LUT tables," Mater. Today Proc., vol. 24, pp. 9599, 2020.

[21] M. G. Villalva, J. R. Gazoli, and E. R. Filho, "Comprehensive Approach to Modeling and Simulation of Photovoltaic Arrays," IEEE Trans. POWER Electron., vol. 24, no. 5, pp. 1198-1208, 2009.

[22] B. Habbati, Y. Ramdani, and F. Moulay, "A detailed modeling of photovoltaic module using MATLAB," NRIAG J. Astron. Geophys., vol. 3, no. 1, pp. 53-61, 2014.

[23] N. M. Noor, et al., "Comparison of Linear Interpolation Method and Mean Method to Replace The Missing Values In Environmental Data Set,” Mater. Sci. Forum, vol. 803, pp. 278-281, 2015.

[24] "Technical Sheet of 135W/ 125W NS-F135G5/NSF125G5 Amorphous Silicon/Microcrystalline Silicon Sharp." [Online]. Available: http://sharp-afg.com/?product=ns-f135g5.

[25] "Technical Sheet of Solar Panel POWERMAX." [Online]. Available: https://fr.enfsolar.com/pv/paneldatasheet/Thin-film/255.

[26] “Technical Sheet of TSM-DC01A- Trina Solar." [Online]. Available: https://static.trinasolar.com/sites/default/ files/Comax_DC01A_Datasheet_Feb13_EN.pdf.

[27] "Technical Sheet of CdTe panel with Thin Film Solar Module Cx3-CALYXO." [Online]. Available: https://fr.enfsolar.com/pv/panel-datasheet/Thin-film/873.

[28] H. Idadoub, M. Kourchi, M. Ajaamoum, D. Yousfi, and A. Rachdy, "Comparison and experimental validation of three photovoltaic models of four technology types,” Int. J. Tech. Phys. Probl. Eng., vol. 11, no. 4, pp. 1-10, 2019. 